\title{
Air Pollution from Traffic at Major Causeway Al-Khobar, Saudi Arabia
}

\author{
Khaled F. Salama' ${ }^{1}$ Mubashir Zafar' ${ }^{2}$ Dulaim Abdullah Alrabea ${ }^{3}$, Abdullah Ali Alqahtani, \\ Suhaib Abdulaziz Almarghoub ${ }^{3}$ and Ali Abdullah Alshehri ${ }^{3^{*}}$ \\ 'Assistant Professor, Department of Environmental Health, College of Public Health, Imam Abdul Rahman Bin Faisal University, \\ Saudi Arabia; ksalama@iau.edu.sa \\ ${ }^{2}$ Assistant Professor, Department Public Health, College of Public Health, Imam Abdul Rahman Bin Faisal University, \\ Saudi Arabia; mzzahmed@iau.edu.sa \\ ${ }^{3}$ Department of Environmental Health, College of Public Health, Imam Abdul Rahman Bin Faisal University, Saudi Arabia; \\ Dulaim11@outlook.com, Env.abdullah@hotmail.com, Suhaib.almarghoub@gmail.com, Alialshehrii07@gmail.com
}

\begin{abstract}
Introduction: Causeway is providing a road link between travelers from Al-Khobar, Saudi Arabia and Bahrain. The vehicle traffic noise and emissions exhaust at Causeway have a significant effect on air quality parameters which leads to deteriorations impact on health of employees and passengers. The present study aimed to analyze the ambient air pollutants $\mathrm{PM} 10, \mathrm{PM}_{2.5}, \mathrm{PM}_{1}, \mathrm{O}_{3}, \mathrm{CO}_{2}$, $\mathrm{SO}_{2}$, CO, VOCs, and $\mathrm{NO}_{2}$, ambient noise and heat stress in and around causeway. Materials and Methods: All gaseous, particulate air pollutants, meteorological factors, ambient noise and heat stress were analyzed using standards calibrated equipment. July 2019 to October 2019 the study incused seven administrative sites in King Fahd causeway (Saudi Side). Air Quality Index (AQI) was used to determine the concentrations of selected ambient air pollutants. Results: All major air pollutants were high and significant difference in the concentration level between weekdays and weekends $(\mathrm{p}<0.05)$ and exceeds the international air quality guidelines in the selected studied sites of causeways. However, ambient noise demonstrated high significant levels in different studied sites in different times $(\mathrm{p}<0.05)$. Conclusion: Air quality measures in Causeway are significantly deteriorated and should be continuously evaluated to minimize the risk of daily exposure to traffic emissions.
\end{abstract}

Keywords: Air, Ambient, Gaseous, Pollutants, Quality

\section{Introduction}

Air quality is one of the basic indicators for environment quality. All urban cities affected by air pollution due to traffic, industries ${ }^{1}$. All developed and specifically developing countries have experienced air pollution because of increasing traffic in all roads in the major urban cities ${ }^{2}$. Population living in these urban cities has high chances of worse health impacts ${ }^{3-5}$.

Previous decades major cause of air pollution by industrial fumes and fossil fuel burning but now traffic is the major source of air pollution especially in major highways ${ }^{6}$. Air pollution caused by traffic which is contributing to severe health impacts such as cancers and ear problems and also effect daily activity ${ }^{7}$. Emission from traffic due to traffic congestion and vehicle moving at slow speed are the major factors ${ }^{8}$. Air pollution from traffic have major public health problem and it is associated with asthma and cardiovascular disease and increase no. of patients visited the emergency department of all hospitals. The particles which contributed these health impacts

\footnotetext{
${ }^{*}$ Author for correspondence
}

are Particulate Matter (PM), Volatile Organic Compounds (VOCs) sulfur dioxide $\left(\mathrm{SO}_{2}\right)$, and carbon monoxide (CO). The most common age group affected is from children and older people $^{9}$. It is estimated 2.4 million deaths per year worldwide due to air pollution from traffic ${ }^{10}$.

It is estimated that $50 \%$ of world population living in urban cities. These pollutants affected the health of urban cities population. Exhaust emissions from vehicle produce pollutants such as carbon monoxide (CO), Particulate Matter (PM), carbon dioxide (CO), hydrocarbons (HC), Sulfur dioxide $\left(\mathrm{SO}_{2}\right)$, Volatile Organic Compounds (VOC), and nitrogen oxides $(\mathrm{NOx})^{11}$. The route of bus fleets represent a substantial portion within the city traffic ${ }^{11}$.

When driver drive the vehicle and there is rush and traffic jam, they exposed to high concentration of pollutants ${ }^{12}$. Now days the auto manufacturers used latest technology for engine specification for reduce the emission but still this pollutants comes from emission which is in the nanoparticle size range less than $50 \mathrm{PM}^{13}$. 
Quality of air depends on many factors but main factors in urban cities traffic pollution and emission strength and meteorological conditions of area $\mathrm{a}^{14}$. The meteorological factors such as: wind speed, wind direction, air temperature, humidity, barometric pressure and height of the mixing layer ${ }^{14}$. These factors can modifies the pollutants concentration in the $\operatorname{air}^{15}$.

The rational of this study is that no previous study was conducted on best of my knowledge which determine the air quality along the major roads in Saudi Arabia. The results of the study will help to develop the policy to reduce the pollutants concentration in air.

The aim of this study is to determine the ambient air quality level major causeway in Saudi Arabia.

\section{Methodology}

\subsection{Sampling Site}

King Fahd caws way authority is an institution that provides entry and exit services between the two countries Kingdom of Saudi Arabia and the Kingdom of Bahrain and length is $25 \mathrm{~km}$. Measurement will be conducted during all weekdays at morning, afternoon and evening time.

For this study, there are seven major sampling stations and for each station at least tow place of sampling to make sure our data is specific and accurate, selected for the purpose of data sampling.

\subsection{Sampling Strategy}

\subsubsection{All gases Emission such as $\mathrm{NO}_{2}, \mathrm{SO}_{2}, \mathrm{CO}_{2}, \mathrm{O}_{3}$, $\mathrm{CO}_{2}$ and VOCs}

Gas Concentration Detector was used to measure the concentration of gas in the atmosphere, Gray wolf Direct Sense Monitoring Kit (Toxic Gas TG-501 PROBE) was used. There were a lot of records for each of the VOCs, $\mathrm{NO}_{2}, \mathrm{CO}_{2}, \mathrm{SO}_{2}, \mathrm{O}_{3}$, $\mathrm{CO}$ levels from customs and passport stations in King Fahd causeway. By real-time dust monitor reading by detecting both repairable and total dust sampling, samples of PM10, PM2.5 and PM1 was analyzed using real-time dust monitor. After calibration in the lab Noise levels were measured using an integrating sound level meter, type 2225, with microphone type 4129 , manufactured by TES Company that gives the average of sound level for a period. Temperature (Temp), wind speed (km/ hour) Wet Bulb globe Temperature (WBGT), Relative Humidity (\%) were calculated using calibrated equipment called (Kestrel).

\subsection{Data Assessment}

Data were analyzed using SPSS software version 23. Descriptive statistics was used to calculate the mean and standard deviations. Mean concentration was computed for the total determining period and intervals with high and low exposure independently. If missing values were observed than the other distances in specific area were excluded to compare the means.

\section{Results}

Data revealed that levels of $\mathrm{VOC}, \mathrm{NO}_{2}, \mathrm{O}_{3}, \mathrm{SO}_{2}, \mathrm{CO}$, are exceeds than the allowable exposure limits and quality guidelines of Saudi Arabia. These concentrations were significantly difference between weekend days and weekdays (Table 1).

Particulate fractions PM10, PM2.5, and PM1 are highly significant in Passport station. Data revealed that levels of PM10, PM2.5, and PM1 are higher than the permissible exposure limits and Saudi air quality guidelines and these reflect the impact of vehicle traffic emissions in the selected area. These levels were significantly difference between weekend days and weekdays (Table 2).

Table 3 demonstrates the variations in the meteorological factors that affect the concentrations of both gaseous and particulate air quality. These levels were significantly difference between weekend days and weekdays.

The mean levels of ambient noise and heat stress where the levels of noise are significantly higher than the permissible levels of noise traffic in weekend than weekdays and these

Table 1. Mean levels of gaseous air pollutants in passport station

\begin{tabular}{|l|c|c|c|}
\hline $\begin{array}{l}\text { Gaseous air } \\
\text { pollutants ppm }\end{array}$ & Weekend & Weekdays & p-value \\
\hline $\mathrm{NO}_{2}$ & 1.4 & 0.98 & $<0.05$ \\
\hline $\mathrm{SO}_{2}$ & 1.1 & 0.87 & $<0.05$ \\
\hline VOCs & 0.9 & 0.75 & $<0.05$ \\
\hline $\mathrm{O}_{3}$ & 0.15 & 0.1 & $<0.05$ \\
\hline $\mathrm{CO} / 10$ & 1.2 & 0.99 & $<0.05$ \\
\hline $\mathrm{CO}_{2} / 1000$ & 0.7 & 0.78 & $>0.05$ \\
\hline
\end{tabular}

Table 2. Mean levels of particulate air pollutants in passport station

\begin{tabular}{|l|c|c|c|}
\hline $\begin{array}{l}\text { Gaseous air } \\
\text { pollutants } \mu \mathrm{g} / \mathrm{m} 3\end{array}$ & Weekend & Weekdays & p-value \\
\hline TSP & 370 & 350 & $<0.05$ \\
\hline PM10 & 257 & 245 & $<0.05$ \\
\hline PM2.5 & 65 & 67 & $>0.05$ \\
\hline PM1.0 & 48 & 33 & $<0.05$ \\
\hline
\end{tabular}

Table 3. Mean levels of meteorological factors in passport station

\begin{tabular}{|l|c|c|c|}
\hline $\begin{array}{l}\text { Meteorological } \\
\text { factors }\end{array}$ & Weekend & Weekdays & p-value \\
\hline Wind Speed & 0.7 & 0.4 & $<0.05$ \\
\hline Temperature & 33.9 & 29.3 & $<0.05$ \\
\hline Humidity & 59 & 74.3 & $>0.05$ \\
\hline
\end{tabular}




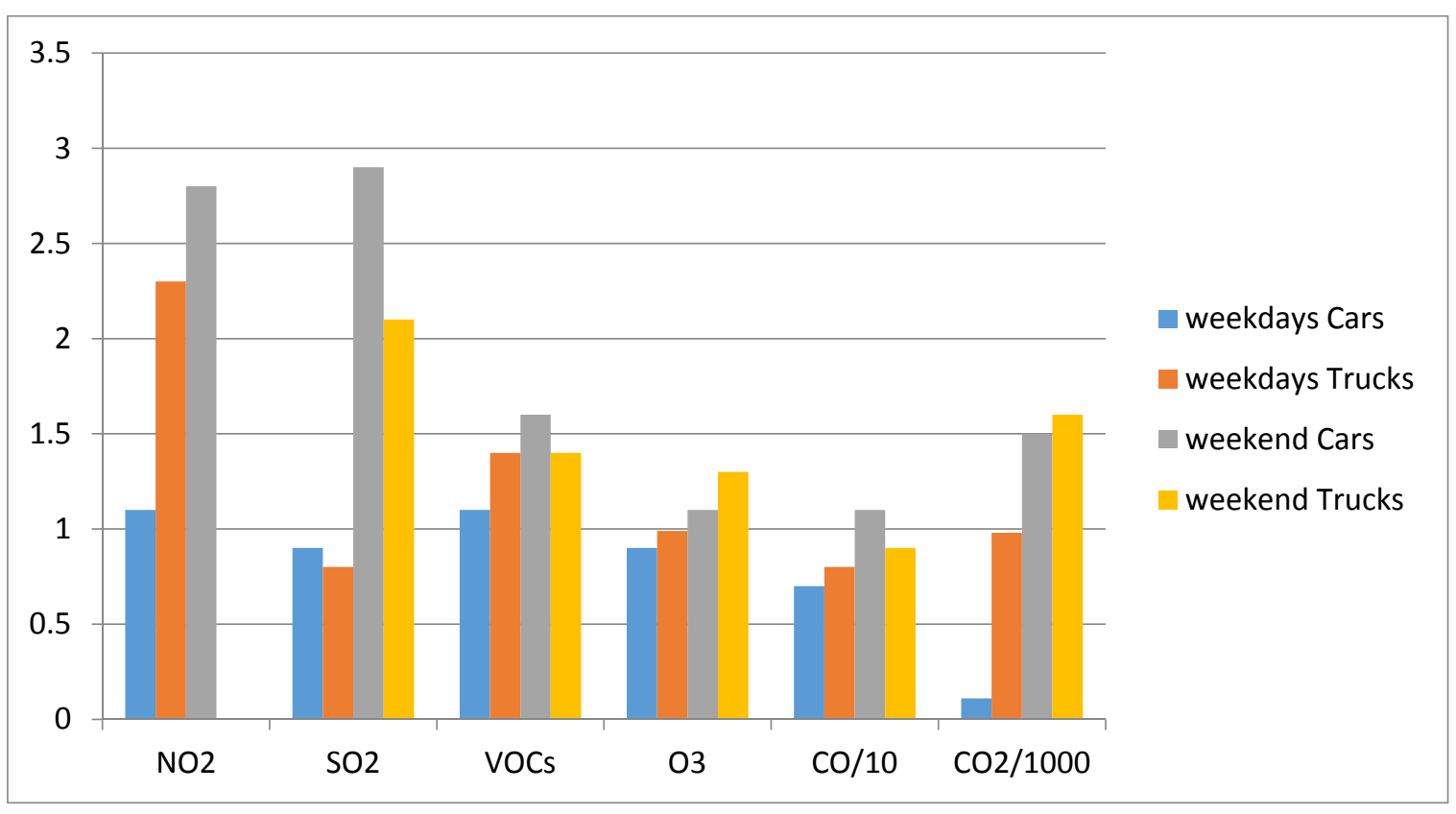

Figure 1. Mean levels of gaseous air pollutants in customs station.

Table 4. Mean levels of noise and heat stress in passport station

\begin{tabular}{|l|c|c|c|}
\hline $\begin{array}{l}\text { Noise and heat } \\
\text { stress }\end{array}$ & Weekdays & Weekend & p-value \\
\hline Noise & 81 & 88 & $<0.05$ \\
\hline WBGT. C $^{\circ}$ & 24.5 & 25.2 & $>0.05$ \\
\hline
\end{tabular}

Table 5. Correlation coefficients between pollutants and traffic volume in different sites through the King Fahd Causeway

\begin{tabular}{|l|c|c|c|}
\hline Air pollutants & $\begin{array}{c}\text { Traffic volume } \\
\text { weekdays }\end{array}$ & $\begin{array}{c}\text { Traffic volume } \\
\text { weekend }\end{array}$ & p-value \\
\hline $\mathrm{CO}$ & 0.57 & 0.87 & $<0.05$ \\
\hline $\mathrm{CO}_{2}$ & 0.45 & 0.63 & $<0.05$ \\
\hline $\mathrm{NO}_{2}$ & 0.35 & 0.74 & $>0.05$ \\
\hline $\mathrm{SO}_{2}$ & 0.41 & 0.84 & $>0.05$ \\
\hline VOCs & 0.31 & 0.71 & $<0.05$ \\
\hline $\mathrm{O}$ & 0.41 & 0.51 & $<0.05$ \\
\hline TSP & 0.54 & 0.89 & $>0.05$ \\
\hline PM Fractions & 0.65 & 0.91 & $<0.05$ \\
\hline
\end{tabular}

might be due to the high traffic movements of cars during the weekend in comparison with the normal traffic movement in the weekdays (Table 4).

Data shows that there is strong correlation coefficient between different air pollutants and traffic volume on weekend days in comparison with weekdays (Table 5). These levels were significantly difference between weekend days and weekdays.

Data revealed that levels of VOCs, $\mathrm{NO}_{2}, \mathrm{O}_{3}, \mathrm{SO}_{2}, \mathrm{CO}$, are exceeds than the allowable exposure limits and quality guidelines by Saudi Arabia (Figure 1).

\section{Discussion}

This study shows that levels of gaseous air pollutants, particulate matters and meteorological factors were high compared to standards level. Also, there is a significant association between levels of gaseous air quality in the weekend and weekday and this might due to the high traffic congestions in the weekend days and increase the travel to Bahrain.

The result of study found that high concentration level of gaseous air pollutants and particulate matters around the causeways. Results of the similar studies showed that $\mathrm{CO}$ and PM10 concentration were higher in highways and these concentrations were high during summer season ${ }^{16-18}$. The data for air quality in the downtown of city showed that weather can affect the variation of concentration of sulfur dioxide $\left(\mathrm{SO}_{2}\right)$, Carbon Monoxide (CO) and PM10 ${ }^{18}$.

Concentrations levels of PM10 and PM2.5 were high near the causeways in this study. Previous study found significantly higher during weekend days. Measurements from the other major roads in western European countries were high especially in weekends ${ }^{19}$. The past study was conducted to determine the 24 hours for whole weeks mean concentration of particulate matters at busy road of Tokyo, Japan. The result found that $\mathrm{PM}$ concentrations has reduced from $57 \mu \mathrm{g} \mathrm{m}^{-3}$ at $1 \mathrm{~m}$ distance 
to $29 \mu \mathrm{g} \mathrm{m}^{-3}$ at $10 \mathrm{~m}$ and $24 \mu \mathrm{g} \mathrm{m}^{-3}$ at $50 \mathrm{~m}^{20}$. Also, there is a significant association between levels of particulate air quality in the weekend and weed day and this might due to the high traffic congestions in the weekend days and increase the travel to Bahrain. However, these findings correlate significantly with the total numbers of cars crossing the causeway during the weekend days.

Measured particulate emissionslevels revealed s significant levels of PM10 and PM2.5 in the studied areas where the highest concentrations were recorded in comparison with Air Quality index. This might due to the extensive use of gasoline as a primary fuel source in all types of vehicles crossing the King Fahd Causeway where it contains much Sulphur in its ingredients and represent environmentally and severe health impacts among working staff in the King Fahd Causeway.

Cars and Turks are the major source of particulate matters and principal contributors of air pollution ${ }^{21,22}$. This pollution has contributed significantly on health of human being ${ }^{21}$. These vehicles constituted from 20 to $21 \%$ of global burden of nitrogen oxides (NOx) and Particulate Matter (PM) emissions respectively in $2010^{23}$. This pollution was due to exhaust emission depends on the driving style, engine condition, type of fuel used. Global CO and NOx emission from the fossil fuel combustion $^{24}$.

There is common practice that low quality of fuel was used in vehicle which contributes the air pollution and second factors is poor regulation of traffic control ${ }^{25}$. This problem increased day by day throughout the world because of poor regulation of environmental regulation ${ }^{26}$.

In this study $\mathrm{CO}$ concentration has increased due to traffic congestion and this finding is consistent with previous study which showed that high traffic density directly associated with $\mathrm{CO}$ concentration. Traffic Congestion also major contributor to $\mathrm{CO}$ concentration ${ }^{27}$.

In this study $\mathrm{NO}_{2}$ concentration also high in all sites with $2.60 \mathrm{ppm}$ concentration level. This level significantly differences between weekdays and weekends $(p>0.05)$ because of traffic volume. This finding also consistent with other study which showed that $\mathrm{NO}_{2}$ concentration were high in major highways. Other factors contribute to $\mathrm{NO}_{2}$ concentration are poor maintenance of vehicle ${ }^{28}$. These levels of $\mathrm{NO}_{2}$ were high compared to $\mathrm{WHO}$ guideline of air quality.

The $\mathrm{SO}_{2}$ concentration was also high at all study sites which is $2.18 \mathrm{ppm}$. The major factors are emission from poor maintenance vehicle. The mean concentration level is above the standard guideline of WHO air quality index. The previous study has found the results that $\mathrm{SO}_{2}$ associated with asthma directly ${ }^{29}$. These caused also several other respiratory problems ${ }^{30}$. That's why residence of that area suffered from respiratory problems.

\section{Conclusion}

We can conclude that King Fahd Causeway Facilities have higher concentrations of gaseous and PM in air that exceed the Saudi and international air quality standards which represent a major health risk to the employees and passengers.

As a mitigation measures, it seems to be difficult to control emissions from vehicles, but we should have others control measures as ventilation, Personal protective equipment, training and administrative measures.

\section{Ethical Approval}

The Institutional Ethical Approval was received from the university.

\section{Consent for Publication}

Received the consent of publication.

\section{Conflict of Interest}

The authors declare that they have no conflict of interest.

\section{Acknowledgment}

None

\section{Authors' Contributions}

All authors contributed equally in the study and participated in its design and coordination and helped to draft the manuscript. They also read and approved the final manuscript.

\section{Reference}

1. Hrdlickova Z, Michalek J, Kolar M, Vesely V. Identification of factors affecting air pollution by dust aerosol PM10 in Brno City, Czech Republic. Atmospheric Environment. 2008; 42(37): 86618673. https://doi.org/10.1016/j.atmosenv.2008.08.017.

2. Atash F. The deterioration of urban environments in developing countries: Mitigating the air pollution crisis in Tehran, Iran. Cities. 2007; 24(6): 399-409. https://doi.org/10.1016/j. cities.2007.04.001.

3. Mansouri, Hoshyari, Mansouri. Study on ambient concentrations of air quality parameters $\left(\mathrm{O}_{3}, \mathrm{SO}_{2}, \mathrm{CO}\right.$ and PM10) in different months in Shiraz city. Iran International Journal of Environmental Sciences. 2011; 1(7): 2.

4. Xie X, Semanjski I, Gautama S, Tsiligianni E, Deligiannis N, Rajan R, Pasveer F, Philips W. A review of urban air pollution monitoring and exposure assessment methods. ISPRS International Journal of Geo-Information. 2017 Dec 1; 6(12): 389. https://doi.org/10.3390/ijgi6120389. 
5. El-Sharkawy M, Zaki G. Traffic pollutants levels at different designs of King Fahd Road, Saudi Arabia: Comparative study. TOJSAT: The Online Journal of Science and Technology. 2012; 2(1): 45-55.

6. Einstein A, Podolsky B, Rosen N. Can quantum-mechanical description of physical reality be considered complete? Phys. Rev. 1935; 47: 777-780. https://doi.org/10.1103/PhysRev.47.777.

7. Ingle ST, Wagh ND, Pachpande BG, Patel VS, Attarde SB. The influence of workplace environment on lung function of shopkeepers working near National Highway in Jalgaon: A note. Transportation Research Part D: Transport and Environment. 2005; 10(6): 476-482. https://doi.org/10.1016/j.trd.2005.04.008.

8. Kassomenos P, Karakitsios S, Papaloukas C. Estimation of daily traffic emissions in a South-European urban agglomeration during a workday- Evaluation of several «what if' scenarios. The Science of the Total Environment. 2006; 370(2-3): 480-490 https://doi.org/10.1016/j.scitotenv.2006.08.018. PMid:16979222.

9. Chimonas MA, Gessner BD. Airborne particulate matter from primarily geologic, non-industrial sources at levels below National Ambient Air Quality Standards is associated with outpatient visits for asthma and quick-relief medication prescriptions among children less than 20 years old enrolled in Medicaid in Anchorage, Alaska. Environmental Research. 2007 Mar 1; 103(3): 397-404. https://doi.org/10.1016/j.envres.2006.08.013. PMid: 17049511.

10. Hertel O, Goodsite ME. Urban air pollution climates throughout the world. Issues in Environmental Science and Technology. 2009 Aug 7; 28: 1. https://doi.org/10.1039/9781847559654-00001.

11. Jayaratne ER, Ristovski ZD, Meyer N, Morawska L. Particle and gaseous emissions from compressed natural gas and ultralow sulphur diesel-fuelled buses at four steady engine loads. Science of the Total Environment. 2009 Apr 1; 407(8): 2845-2852. https:// doi.org/10.1016/j.scitotenv.2009.01.001. PMid: 19185331.

12. Zhang F, Wang W, Lv J, Krafft T, Xu J. Time-series studies on air pollution and daily outpatient visits for allergic rhinitis in Beijing, China. [Article]. The Science of the Total Environment. 2011; 409(13): 2486-2492. https://doi.org/10.1016/j. scitotenv.2011.04.007. PMid: 21514624.

13. Boverhof DR, Gollapudi BB. Editors. Applications of Toxicogenomics in Safety Evaluation and Risk Assessment. John Wiley \& Sons; 2011 Oct 11. https://doi.org/10.1002/ 9781118001042. PMid: 21447610.

14. Jespen T. ATEX-Explosive Atmospheres. Springer Series in Reliability Engineering. 2016. https://doi.org/10.1007/978-3-319-31367-2.

15. Seehusen F, Felderer M, Großmann J, Wendland MF. Editors. Risk Assessment and Risk-Driven Testing: Third International Workshop, RISK 2015, Berlin, Germany; June 15, 2015. Revised Selected Papers. Springer 2015 Nov 12. https://doi. org/10.1007/978-3-319-26416-5.

16. Moolla R, Curtis JC, Knight J. occupational exposure of diesel station workers to BTEX compounds at a bus Depot. Int. J. Environ. Res. Public Health. 2015; 12: 4101-4115. https://doi.org/10.3390/ ijerph120404101. PMid: 25872020, PMCid: PMC4410235.

17. Lu Y. Traffic-Related PM2. 5 Air Pollution and Schools in Proximity to Major Roadways in Shanghai, China (Doctoral dissertation), University of Washington; 2016. http://hdl.handle. net/1773/36863.
18. Nedal T. Ratrouta, Uneb Gazdera, El-Sayed M. El-Alfy. Effects of using Average Annual Daily Traffic (AADT) with exogenous factors to predict daily traffic. Science Direct. 2014; 325-327. https://doi.org/10.1016/j.procs.2014.05.431.

19. Song J, Zhao C, Lin T, Li X, Prishchepov AV. Spatio-temporal patterns of traffic-related air pollutant emissions in different urban functional zones estimated by real-time video and deep learning technique. Journal of Cleaner Production. 2019 Nov 20; 238:117881. https://doi.org/10.1016/j.jclepro.2019.117881.

20. Nakatsuka $H$, Watanabe $T$, Ikeda $M$, Hisamichi $S$, Shimizu $\mathrm{H}$, Fujisaku S, Ichinowatari Y, et al. Comparison of the health exects between indoor and outdoor air pollution in northeastern Japan. Environment International. 1991; 17: 51-59. https://doi. org/10.1016/0160-4120(91)90337-P.

21. Kan H, Chen R, Tong S. Ambient air pollution, climate change, and population health in China. Environment International. 2012 Jul 1; 42: 10-9. https://doi.org/10.1016/j.envint.2011.03.003. PMid: 21440303.

22. Wu QZ, Wang ZF, Gbaguidi A, Gao C, Li LN, Wang W. A numerical study of contributions to air pollution in Beijing during CAREBeijing-2006. Atmospheric Chemistry and Physics. 2011 Jun 24; 11(12): 5997-6011. https://doi.org/10.5194/acp-11-5997-2011.

23. Fischer PH, Brunekreef B, Lebret E. Air pollution related deaths during the 2003 heat wave in the Netherlands. Atmospheric Environment. 2004 Mar 1; 38(8): 1083-1085. https://doi. org/10.1016/j.atmosenv.2003.11.010.

24. Ayub S, Baig K. Monitoring the influence of outdoor vehicular pollutants concentration on indoor air quality of the houses located close to urban roadway/highways. European International Journal of Science and Technology. 2013; 2(3): 170-180.

25. Okunola OJ, Uzairu A, Gimba CE, Ndukwe GI. Assessment of gaseous pollutants along high traffic roads in Kano, Nigeria. International Journal of Environment and Sustainability. 2012 May 16; 1(1). https://doi.org/10.24102/ijes.v1i1.39.

26. Olajire AA, Azeez L, Oluyemi EA. Exposure to hazardous air pollutants along Oba Akran road, Lagos-Nigeria. Chemosphere. 2011 Aug 1; 84(8): 1044-1051. https://doi.org/10.1016/j. chemosphere.2011.04.074. PMid: 21624630.

27. Han X, Naeher LP. A review of traffic-related air pollution exposure assessment studies in the developing world. Environment International. 2006 Jan 1; 32(1): 106-120. https:// doi.org/10.1016/j.envint.2005.05.020. PMid: 16005066.

28. Kaasik M, Kimmel V. Validation of the improved AEROPOL model against the Copenhagen data set. International Journal of Environment and Pollution. 2003 Jan 1; 20(1/6): 114-120. https:// doi.org/10.1504/IJEP.2003.004256.

29. Xia T, Nitschke M, Zhang Y, Shah P, Crabb S, Hansen A. Trafficrelated air pollution and heal th co-benefits of alternative transport in Adelaide, South Australia. Environment International. 2015 Jan 1; 74: 281-290. https://doi.org/10.1016/j.envint.2014.10.004. PMid: 25454245.

30. Augustine C. Impact of air pollution on the environment in Port Harcourt, Nigeria. Journal of Environmental Science and Water Resources. 2012; 1(3): 46-51. 